UCRL-ID-118656

\title{
Small-Scale Cookoff Bomb (SSCB) Tests on Solutions of DMSO/LX-10-1 and DMSO/PBX-9404
}

\author{
F. Helm \\ D. M. Hoffman
}

\section{RECEIVED \\ NOV 171995 \\ OSTI}

September 28, 1994

This is an informal report intended primarily for internal or limited external distribution. The opinions and conclusions stated are those of the authorand may or may not be those of the Laboratory.

Work performed under the auspices of the U.S. Department of Energy by the Lawrence Livermore National Laboratory under Contract W-7405-Eng-48. 


\section{DISCLAIMER}

This document was prepared as an account of work sponsored by an agency of the United States Government. Neither the United States Government nor the University of California nor any of their employees, makes any warranty, exprese or implied, or assumes any legal liability or responsibility for the accuracy, completeness, or usefulness of any information, apparatus, product, or process disclosed, or represents that its use would not infringe privately owned rights. Reference herein to any specific commercial product, process, or service by trade name, trademark, manufacturer, or otherwise, does not necessarily constitute or imply its endorsement, recommendation, or favoring by the United States Government or the University of Califomia. The views and opinions of authors expressed herein do not necessarily state or reflect those of the United States Government or the University of California, and shall not be used for advertising or product endorsement purposes.

This report has been reproduced directly from the best available copy.

Available to DOE and DOE contractors from the

Office of Scientific and Technical information

P.O. Box 62, Oak Ridge, TN 37831

Prices available from (615) 576-8401, FTS 626-8401

Available to the public from the

National Technical Information Service

U.S. Department of Commerce 5285 Port Royal Rd.

Springfield, VA 22161 


\section{DISCLAMMER}

Portions of this document may be illegible in electronic image products. Images are produced from the best available original document. 


\section{Small-Scale Cookoff Bomb (SSCB) Tests on Solutions of DMSO/L $\dot{X}-10-1$ and DMSO/PBX-9404*}

\section{INTRODUCTION}

The small-scale cookoff bomb test was developed by the Navy at China Lake as a method for evaluation of the violence of thermal decomposition of explosives and propellants. ${ }^{1-3}$ The UN "Recommendations on the Transport of Dangerous Goods Tests and Criteria" (ST/SG/AC.10/11) ${ }^{4}$ have accepted the small-scale cookoff bomb test as a test for classification of a substance as an explosive (class 1 substance) for storage and shipment. The US Departments of Transportation and Defense ${ }^{5}$ have agreed to use the UN tests as US criteria for storage and shipment. The UN scheme is designed to assess the relative hazard of explosives so that an appropriate classification for transport can be made by the competent authority (DOT). Test series 1 indicates whether a substance not designed to have an explosive effect, has potentially explosive properties. There are two kinds of tests in UN series 1: shock sensitivity tests to determine if the substance will propagate to a detonation and thermal tests to determine its thermal response. Three thermal tests have been approved: the Koenen test, the internal ignition test and the small-scale cookoff bomb (SSCB) test.

Lawrence Livermore National Laboratory has designed a dissolution work station for removal of the plastic bonded explosives (PBXs) LX-10-1 and PBX-9404 from two artillery fired atomic projectiles (AFAPs) using dimethyl sulfoxide (DMSO) as the solvent. The DOE Explosives Safety Manual ${ }^{6}$ allows up to $33 \%$ solutions of explosives to be handled as non-explosive in the laboratory and $25 \%$ solutions to be stored as nonexplosives unless the explosive precipitates out. Typical runs in the dissolution work station produce less than 10\% solutions of explosive in DMSO. If the solvent were inadvertently run twice, there would still be less $\mathrm{HMX}$ in those solutions than the maximum allowed by the DOE. Prior to the large-scale dissolution work station operation, small-scale safety tests were used as an estimate of the hazards associated with up to $33 \%$ of these explosives in DMSO. No unusual results were observed for these explosives in DMSO.

In order to ship solutions of LX-10-1 or PBX-9404 in DMSO on US highways for waste or recycling as non-explosives, these solutions must be approved for shipping by the DOT based on the results of UN test series 1 . The compositions of LX-10-1 and PBX-9404 are given in Table 1. The shock sensitivity of solutions of these two plastic bonded explosives in dimethyl sulfoxide (DMSO) has been evaluated using the UN series 1 gap test for liquids as described in a previous report. ${ }^{7}$ The purpose of this paper is to present the results of the SSCB tests on pure DMSO and $25 \% \mathrm{PBX}$ solutions in DMSO to assist in the classification of these solutions 
Table 1. Compositions of LX-10-1 and PBX-9404.

\begin{tabular}{ccc}
\hline Composition & PBX-9404 & LX-10-1 \\
\hline HMX & 94 & 94.5 \\
NC & 3 & \\
CEF & 3 & \\
Viton A & & 5.5 \\
\hline
\end{tabular}

notes: $\mathrm{NC}=$ nitrocellulose; $\mathrm{CEF}=$ chloroethyl phosphate.

The small-scale cookoff bomb (SSCB) test simulates transport and storage situations involving slow external heating of a substance. This test was chosen from the available UN class 1 thermal tests because of its simplicity and the High Explosives Applications Facility Safety Procedures which would require written prior review or operating safety procedures to use black powder (used in internal ignition test) or flammable gas (propane - used in Koenin test) in the one $\mathrm{Kg}$ firing tank. Figure 1 shows the schematic of the experimental arrangement. Approximately $400 \mathrm{cc}$ of 75/25:DMSO/PBX solution were added to 6 SSCBs, one set of 3 for the PBX 9404 solutions and another for the LX-10-1 solutions. A control and a test thermocouple (on opposite sides of the vessels outer wall) and a third thermocouple (inside of the vessel near the center) were monitored during the tests. Sufficient ullage was allowed to prevent the liquid volume from exceeding $400 \mathrm{ccs}$ at $400^{\circ} \mathrm{C}$. The tests were heated from ambient to $400^{\circ} \mathrm{C}$ at a programmed heating rate of $3^{\circ} \mathrm{C} / \mathrm{min}$. The time and temperature of the explosive reaction was taken from the thermocouple records. To pass the UN series 1 criteria, the SSCB must remain in one piece (not ruptured or fragmented) and the witness plate cannot be deformed or punctured. 5 The UN series 1 criteria are not met if any of the following occur: (1) the SSCB is ruptured, (2) the SSCB is fragmented, (3) the witness plate is deformed, or (4) the witness plate is punctured.

The UN series 1 test requirements for passing the SSCB test are quite severe. For comparison the internal ignition test, which ignites the substance with black powder and has similar confinement, allows the pipe to be split or laid open or the cap to be distorted to the point at which it is blown off and still pass the UN series 1 criteria.

The SSCB was originally developed by Pakulak as a scaled down version of the DOD fast and slow cookoff tests, which are large scale cookoff tests required for main charge explosives, propellants and pyrotechniques qualification. 8,9 The SSCB has been used extensively by Pakulak, et al. ${ }^{1-3}$ to evaluate the violence of thermal explosions in current explosives and to develop thermally insensitive propellants and explosives. Based on the deformation of the witness plate and the number of fragments obtained after the test, a rating system ${ }^{3}$ from 0 to 10 was assigned to indicate the severity of the reaction. If no change in vessel condition and no dent in the witness plate occurred then the cookoff reaction was classified as burning with a rating of zero. If the vessel was intact but bulged, and no dent was observed in the witness plate, the reaction was also classified as a burn but with reaction rating of 1 . If the vessel was opened and in one piece with less than $0.13 \mathrm{~cm}$ dent $(0.05 \mathrm{inch})$, the reaction was classified as a deflagration with a rating of 2 . 
More pieces and/or deeper dents increased the degree of damage from deflagration to explosion (5 or more large pieces and dent deeper than $0.127 \mathrm{~cm}\left(0.05^{\prime \prime}\right)$ ) to partial or complete detonation (many small pieces, hole or almost punched hole in witness plate) with a maximum rating of 10 . The "dent" in the witness plate is associated with explosive reaction of the substance causing the bottom plate of the vessel to fly across the gap and leave an imprint and not with the buckling of the plate caused by expansion of the vessel. Also reaction times of thermal explosions and detonations should be seconds or less on the thermocouple readouts. Using this rating, the DMSO/PBX solutions would be classified 2 or below, clearly not detonable.

\section{PRELIMINARY TESTING}

Preliminary evaluation of solutions of PBX-9404 and LX-10-1 in DMSO was accomplished using small-scale safety testing techniques. Whenever new explosive mixtures are made, it is LLNL policy to evaluate their explosive sensitivity using a series of 5 small-scale tests. 10,11 Of these tests, only friction sensitivity is not run on liquid samples. A general overview of small-scale testing and the caveats associated with the various tests can be found in reference 12 . A simple estimate of the pressure in the SSCB from $H M X$ decomposition was also made.

\section{Small-scale Safety Testing}

Drop Hammer (DH) tests: 11 The drop hammer offers a means of evaluating impact sensitivity by dropping a $2.5 \mathrm{~kg}$ weight from a variable height onto a small sample of explosive (generally about $35 \mathrm{mg}$ ). The criterion for "explosion" is an arbitrary level of sound produced by the explosive on impact. The distance in centimeters required to achieve this "explosion" in $50 \%$ of the samples tested, $\mathrm{DH}(50)$, is determined by the Bruceton statistical method using 10 drops of varying height. If the sample fails to explode, the result is shown by a $>177 \mathrm{~cm}$ value (the maximum height of the drop tower). Values for LX-10-1, PBX-9404, and their 33\% solutions are given in Table 2. Note, drop heights for solids and liquids should not be compared directly since initiating mechanisms differ, but clearly these liquids are not impact sensitive as measured by this test.

Chemical Reactivity Test (CRT): 13 The LLNL CRT test analyzes selected gasses known to be decomposition products of a variety of common nitramine explosives. The test is generally run on $0.25 \mathrm{~g}$ of sample for $22 \mathrm{~h}$ at $120^{\circ} \mathrm{C}$. If a one gram sample generates more than $2 \mathrm{cc}$ of gas (all species analyzed), it is considered suspect and generally receives further evaluation at 100 or $80^{\circ} \mathrm{C}$. One cc of gas/g of sample is approximately $0.1-0.2 \%$ decomposition of the explosive ingredients. Values of LX-10-1, PBX-9404, and their $33 \%$ solutions are given in Table 2. HMX decomposition in solution is accelerated by almost an order of magnitude compared to crystalline HMX in LX-10-1 as indicated by the increase in CRT gas. Even with this acceleration, decomposition is not sever enough to cause concern. 
Differential Scanning Calorimetry (DSC): ${ }^{14,15}$ The onset of the explosive decomposition exotherm has been used by LLNL and other explosives laboratories as an indication of the thermal stability of explosive materials. For explosives which exhibit global rate constants, the DSC exotherm can be fitted to the Frank-Kamenetskii relationship to predict decomposition temperatures of larger quantities of the material. Values of the DSC onset temperatures for LX-10-1, PBX-9404, and their $33 \%$ solutions are given in Table 2. The DSC traces for these materials are shown in Figures 2-5. DSC data from the solutions shows vaporization of the DMSO at $\sim 180^{\circ} \mathrm{C}$ followed by the HMX thermal decomposition exotherm. In PBX-9404 decomposition of HMX can be accelerated by the presence of Nitrocellulose (NC) and chloroethyl phosphate (CEF). This acceleration is dependent on the heating rate and sample size but is not appreciable for milligram quantities in the DSC traces at $10^{\circ} \mathrm{C} / \mathrm{min}$. The insert in the PBX-9404 trace shows the decomposition of the NC. The insert in the LX-10 trace shows the crystalcrystal transition of HMX with temperature. The acceleration of HMX decomposition by nitrocellulose has not been observed in small quantities of the 33\% solutions of PBX-9404 or in the recrystallized material tested to date. No unusual thermal behavior was observed in the solutions or the explosives.

Electrostatic discharge (Spark) tests: ${ }^{16}$ The LLNL spark sensitivity test is a point to plane geometry version of the approaching electrode ESD test developed by the US Army at Picatinny Arsenal. In this test $1 \mathrm{~J}$ of energy is input into a sample $(-20 \mathrm{mg})$ of explosive through a $500 \Omega$ resistance to simulate static discharges from personnel. Usually the sample is contained in a ring situated on top of a mild steel cylinder $1.97 \mathrm{~cm}$ $\left(0.75^{\prime \prime}\right)$ in diameter $\times 0.76 \mathrm{~cm}\left(3^{\prime \prime}\right.$ high and covered with 2 mil mylar tape to prevent premature discharge. Table 2 shows that both liquids and both solid explosives are not sensitive to spark in this test.

Table 2. Small-scale Safety Testing of LX-10-1, PBX-9404 and their Solutions in DMSO.

\begin{tabular}{lllll}
\hline Sample & 9404 & + DMSO & LX-10-1 & + DMSO \\
\hline DH(50) & $33 \mathrm{~cm}$ & $>177 \mathrm{~cm}$ & $44 \mathrm{~cm}$ & $>177 \mathrm{~cm}$ \\
Friction (BAM-Kg) & 18.0 & $\mathrm{NA}^{*}$ & 16.4 & $\mathrm{NA}^{*}$ \\
CRT cc/.25g & 0.36 & 0.56 & 0.04 & 0.49 \\
DSC T(onset) & $180^{\circ} \mathrm{C}$ & $262^{\circ} \mathrm{C}$ & $250^{\circ} \mathrm{C}$ & $270^{\circ} \mathrm{C}$ \\
Spark & Not sen & Not sen & Not sen & Not sen \\
\hline
\end{tabular}

* Not applicable to liquids

Although they are only preliminary tests, the small-scale tests results clearly show no unexpected explosive hazards associated with handling $25-33 \%$ solutions of these HMX based explosives.

\section{Decomposition of HMX}


Prior to performing the small-scale cookoff testing, an estimate of the gas pressure generated by complete decomposition of HMX in the DMSO was made. If only the pressure rise due to HMX decomposition is accounted for and the decomposition products are:

$$
\mathrm{C}_{4} \mathrm{H}_{8} \mathrm{O}_{8} \mathrm{~N}_{8} \rightarrow 4 \mathrm{CO}+4 \mathrm{~N}_{2}+4 \mathrm{H}_{2} \mathrm{O}
$$

then one mole of dissolved HMX generates 12 moles of gas. Assuming all the HMX from solution ( $400 \mathrm{cc}$ is the volume of the vessel) is decomposed to gasses which are insoluble in DMSO, then the volume fraction of HMX in the $25 / 75$ solution of DMSO/PBX is 0.161 (assuming volume additivity and no ullage). The volume available to the decomposition gasses in this case is $0.064 \mathrm{~L}$. From the ideal gas law

$$
\mathrm{p}_{1} \mathrm{~V}_{1} / \mathrm{T}_{1}=\mathrm{p}_{2} \mathrm{~V}_{2} / \mathrm{T}_{2}
$$

the pressure in the vessel at $400^{\circ} \mathrm{C}$ will be $434 \mathrm{MPa}$ (63 Ksi). If the thin wall assumption is used, the hoop stress $(\sigma)$ on a cylinder wall is given by:

$$
\sigma=\mathrm{pr} / \mathrm{t}
$$

where $p$ is the pressure, $r$ is the cylinder radius $(3.12 \mathrm{~cm})$ and $t$ is the wall thickness $(0.318)$. Then the stress at the wall will be $4.34 \mathrm{GPa}(630 \mathrm{Ksi})$. The yield stress of cold rolled steel is $524 \mathrm{MPa}$ ( $76 \mathrm{Ksi})$. Clearly, these conditions predict the vessel should burst unless the pressure is leaked off when the seal fails or the assumptions are in error. Therefore there is no possibility of passing the UN test as written, since the maximum test temperature is $400^{\circ} \mathrm{C}$ and the critical temperature of $\mathrm{HMX}$ in a $6.4 \mathrm{~cm}\left(2.5^{\prime \prime}\right)$ diameter cylinder is only $218^{\circ} \mathrm{C} .14$

\section{SMALL-SCALE COOKOFF TESTS}

The SSCBs were wrapped with fiberglass insulation to minimize heat loss and set on a solid aluminum cylinder inside the large cylindrical steel shrapnel shield used to protect the firing tank. An aluminum cover plate was placed on top of the shrapnel shield.

Based on the simple calculations above, the results from the cookoff experiments are not surprising. All of the $6 \mathrm{DMSO} / \mathrm{PBX}$ tests and the pure DMSO failed the UN series 1 criteria for the SSCB test. Generally, failure occurred between the threaded cap and body. When this type of failure occurred, the lower witness plate was deformed. According to Pakulak's methodology ${ }^{3}$ this would be rated between $0-1$ and called "burning". In two cases the vessel ruptured at the cylinder wall. When the vessel ruptures, the bolts are bent, heater bands are split and the damage is more severe. However, the vessel could always be recognized, no fragments were observed and the witness plate was undented. According to Pakulak's methodology ${ }^{3}$ this would be rated 
between 1-2 and called "burning or deflagration". For the SSCB test using pure DMSO, threads sheared apart and the witness plate was deformed to about the same extent as test 4 of the PBX/DMSO tests. In one case, the SSCB vented with sufficient force and appropriate direction to propel the SSCB over the top of the large steel cylinder. The electrical wiring for the heaters was not broken and the SSCB was hanging over the outside edge of the shrapnel shield when the tank was opened. Usually the pressure from venting would knock the SSCB off the aluminum cylinder and down into the shrapnel shield. An assembled SSCB and the inside of the 1-Kg firing tank after a test are shown in Figure 6.

The conditions in the firing tank before and after each test are given in Table 3. The pressure $(\Delta \mathrm{P})$ in the tank increased by $9650-12400 \mathrm{~Pa}(14-18 \mathrm{psi})$ after each test. The air temperature in the tank varied from a few degrees up to $75^{\circ} \mathrm{C}$ in different tests. The increase in temperature $(\Delta \mathrm{T})$ of the air in the tank was probably associated with whether or not the DMSO solutions caught fire on the heater bands while being sprayed from the vessel. The type of failure, extent of reaction (burning, deflagration, thermal explosive, partial or full detonation) and rating value from reference 3 are also listed in the table.

A typical plot of the thermocouple readouts has been expanded in Figure 7 to show the central thermocouple temperature (filled diamonds) lagging behind the wall thermocouple (opened squares) by $4-10^{\circ} \mathrm{C}$. The onset $\left(\mathrm{T}_{\text {on }}\right.$ ) of thermal decomposition is indicated by the deviation of the central thermocouple from its initial slope. The temperature at which the maximum thermal decomposition rate intersects the original slope is taken as the "critical" temperature $\left(\mathrm{T}_{\text {crit }}\right)$. These temperatures and their associated times are recorded for each test in Table 4. Usually the thermocouples continued to read for approximately 6-10 minutes ( $\Delta$ time in the table).

The three DMSO/PBX-9404 SSCB test postmortem results are shown in Figure 8. Test 1 (top photograph) failed at the threads between the cap and body. Approximately $0.4 \mathrm{~cm}\left(1 / 4^{\prime \prime}\right)$ of the threads had been sheared completely off around the top of the vessel. The Teflon o-ring was pushed out through the opening between the cap and vessel and can be seen in the upper right-hand corner of the top photo. As the lower witness plate is weaker and not reinforced by the thick cap, it buckled. The lower witness plate in test 1 was bowed almost parabolically with about $1 \mathrm{~cm}\left(3 / 8^{\prime \prime}\right)$ depression along an edge. The bottom of the vessel which was welded to the cylinder making up the rest of the vessel was intact but bowed slightly. All four of the bolts holding the lower witness plate on were bent outward approximately 20 degrees, but not broken. The sides of the vessel were intact with heater bands and wiring and thermocouple wires still in place. No liquid was recovered and the temperature in the tank increased as indicated in Table 3 . Scorch marks were observed on the insulation and around the vessel near the electrical contacts, so it is assumed that some of the DMSO ignited and burned as it was expelled from the vessel. Figure 9 shows the thermocouple readout from test 1 . Between 228 and $232^{\circ} \mathrm{C} \mathrm{a}$ large exotherm occurred. The exotherm occurred at 70.1 minutes into the run. High temperatures $\left(780-1370^{\circ} \mathrm{C}\right)$ were recorded in the center of the vessel for several minutes 
indicating that the reaction was a burn rather than a thermal explosion or detonation. The inside of the vessel was blackened also.

In test 2 the vessel ruptured along its length when the internal stresses from the pressure exceeded the yield strength of the steel (see Figure 8 middle photo). This high pressure failure buckled two bolts on opposite sides of the fixture and left the other two bolts almost intact. The welded bottom of the vessel was completely separated from the vessel along the weld line. The standoff washer and bottom of the vessel are shown at the right in photo. Note also the split heater bands caught between the bolts and the SSCB vessel. The bottom witness plate was flat and undamaged with no indication of a dent from the vessel bottom being thrown across the gap between it and the standoff washer in a detonation. The thermocouple readouts are plotted in Figure 10. The dotted line is the wall thermocouple which stopped reading when the vessel burst ( 73.5 minutes into the run), almost 1.5 minutes after the onset of the exotherm. This long delay between the onset of dẹcomposition and the rupture of the vessel implies that a thermal explosion did not occurred.

Table 3. Firing Tank Test Parameters for SSCB Tests.

\begin{tabular}{ccccccc}
\hline Test ID \# & Temp & $\Delta \mathrm{T}$ & $\Delta \mathrm{P}$ & Failure & Scale & $\begin{array}{c}\text { Type } \\
\text { Reaction }\end{array}$ \\
\hline PBX-9404 & $\left({ }^{\circ} \mathrm{C}\right)$ & $\left({ }^{\circ} \mathrm{C}\right)$ & $(\mathrm{psi})$ & & & \\
$1(542)$ & 23 & 47 & $\mathrm{NM}$ & threads & $\mathrm{R} 1$ & burn \\
$2(543)$ & 20 & 55.0 & 14.3 & wall & $\mathrm{R} 2$ & deflagration \\
$3(544)$ & 20 & 51.1 & 17.9 & threads & $\mathrm{R} 1$ & burn \\
LX-10-1 & & & & & & burn \\
$4(545)$ & 20 & 13.3 & 17.9 & threads & $\mathrm{R} 1$ & burn \\
$5(547)$ & 20 & 40.4 & $\mathrm{NM}$ & threads & $\mathrm{R} 1$ & deflagration \\
$6(551)$ & 20 & 3.3 & 14.2 & wall & $\mathrm{R} 2$ &. \\
DMSO only & & & & & & burn \\
13 (558) & 20 & 4.3 & 16.1 & threads & $\mathrm{R} 1$ & \\
\hline
\end{tabular}

Notes: $\mathrm{NM}=$ not measured.

The third SSCB test failed in the threads also (see Figure 8 lower photo). However, in this test approximately $2 / 3$ 's of the cap remained attached to the vessel and the threads which were visible were not so severely stripped as in test 1 . Again the lower witness plate buckled about $0.4 \mathrm{~cm}\left(1 / 4^{\prime \prime}\right)$ along the edge and the bolts were all bent at the bottom about 20 degrees. A strong sulfur oxide smell on the remains from this test was evidence of decomposition of the DMSO. The thermocouple readouts for test 3 are given in Figure 11.

The three postmortem SSCB test results on 25/75 weight percent LX-10-1/DMSO solutions are shown in Figure 15. The onset of the decomposition exotherm in LX-101/DMSO mixtures tended to be $-5^{\circ} \mathrm{C}$ higher than PBX-9404 (See Table 4). The 
thermocouple readouts for test 4 (Figure 12) show that very high temperatures were recorded in the center of the vessel, as was observed with the PBX-9404 experiments. Note that the vessel temperatures may be even higher than indicated, as the upper temperature limit of the thermocouple readout was $1370^{\circ} \mathrm{C}$.

In test 4 , the cap remained securely attached to approximately $50 \%$ of the vessel and only a relatively small hole could be seen where the liquid had escaped (see top photo in Figure 15). The bottom witness plate was deformed about $0.5 \mathrm{~cm}\left(3 / 16^{\prime \prime}\right)$ on an edge and all four bolts were bent where they passed through the witness plate by about 20 degrees. No evidence of a dent in the witness plate associated with the impact of the vessel bottom was observed. The bottom of the vessel was intact and the sides had not bulged out detectably. Scorch marks were found near the electrical connections on the heater bands. No charring was found on the opposite side of the vessel.

In test 5 (middle photo in Figure 15) the temperature only reached $680^{\circ} \mathrm{C}$ (see Figure 13), but this vessel also failed in the threads and the lower witness plate was deformed to roughly $0.4 \mathrm{~cm}\left(1 / 4^{\prime \prime}\right)$. Again all 4 bolts were bent outward at the bottom witness plate. Cables and thermocouple wires were recovered intact.

Table 4. Thermal characteristics of SSCB thermocouple readouts.

\begin{tabular}{lllllll}
\hline Test & Ton (C) & Tcrit (C) & time(on) & time(crit) & $\Delta$ Tmax & $\Delta$ time \\
\hline 1 & 202 & 213 & 66.3 & 70.1 & 1370 & 6.7 \\
2 & 205 & 219 & 67.9 & 71.6 & 1370 & - \\
3 & 200 & 208 & 66.3 & 69.7 & 1100 & 6.3 \\
4 & 213 & 220 & 73.6 & 75.3 & 1370 & - \\
5 & 216 & 223 & 73.1 & 74.0 & 680 & 4.9 \\
6 & 206 & 217 & 69.2 & 74.8 & 1370 & - \\
7 & 214 & 222 & 72.5 & 74.8 & 680 & 5.0 \\
\hline
\end{tabular}

In test 6 (see lower photo in Figure 15), the vessel wall ruptured, (as in test 2 with PBX-9404). Again the wall thermocouple readout stops approximately two minutes into the exotherm (see Figure 14), implying long times compared to detonation time scales. When the vessel burst, the heater bands split and two bolts on opposite sides of the vessel were deformed in the center (one actually fractured). The bolts adjacent to those which were bent remained unaffected. In both tests 2 and 6 the wall of the vessel sheared at approximately 45 degrees to the circumferential tangent line. The welded bottom of the vessel and the cap were both separated from the vessel wall but the threads were only slightly deformed. Again in this case the lower witness plate was not deformed or dented. The inside of the vessel and some recovered insulation were black from burning.

As a control, pure DMSO was tested in one SSCB (test 7). Although the results were less violent, DMSO also failed to survive to $400^{\circ} \mathrm{C}$. The SSCB failed at the threads 
and the lower witness plate was buckled as can be seen in Figure 16. The thermocouple readouts were very similar to test 5 (compare Figure 17 with Figure 13). The onset of the decomposition exotherm falls within the observed range for the LX-10-1 tests (see Table 4). Clearly, there is very little difference between the test results for all the tests where failure occurs between the threads of the cap and vessel body.

\section{CONCLUSIONS}

According to the ratings developed by Pakulak, ${ }^{3}$ the small-scale safety cookoff bomb tests on 25\% solutions of two explosives (PBX-9404 and LX-10-1) in dimethyl sulfoxide (DMSO) indicate that these solutions are not detonable by thermal excursions under these conditions.

In 5 of the 7 tests, the cap and body of the vessels were sheared apart at the threads. Comparison with the photos in reference 3 indicates this result is comparable to "intact but bulged". The type of reaction would be rated as a 1 (burning) because the vessel was open. In two tests (\#2 with PBX-9404 and \#6 with LX-10-1) the vessel failed along its length when the pressure exceeded the strength of the steel. This also leaves the vessel in one piece, or in two pieces depending on whether the bottom is considered a piece. This result would be rated 2 (deflagration) when there is a dent of $0.13 \mathrm{~mm}$ (0.05"). After talking to Jack Pakulak, the "dent" referred to in the reference is associated with the bottom of the vessel flying across the standoff washer and denting the witness plate. This result was not observed. The witness plate was buckled over its entire area with no imprint from the bottom of the vessel but occasionally an imprint from the soot of burning marked the position of the standoff washer. This result is consistent with burn or deflagration reactions observed by Pakulak. In no case was the damage sufficient to warrant classification as an explosion or detonation. Clearly, pressures on the order of $520 \mathrm{MPa}(76,000 \mathrm{psi})$ were generated from the decomposition process (sufficient to yield the steel). However, the records of the thermocouples and the low violence of the results indicate that no thermal explosion or detonation occurred.

These solutions are expected to be shipped in $40-55$ gallon drums. The wall thickness of these drums will be less than the SSCB and the radius much larger. In the event of a fire the critical stresses and pressure at failure would be substantially less and the violence of reaction would also be less. The hazard is expected to be similar to other flammable solvents shipped in like manner unless the HMX precipitates out. If this occurs because of the density differences between DMSO and HMX, the higher density HMX would precipitate to the bottom of the drum. In this case, the explosive would behave like water-wet HMX. One scenario for this to happen would be for moisture or other liquid to be absorbed by the DMSO, reducing its solubility for HMX. If solutions were packed with sufficient moisture absorber to prevent precipitation, the cookoff tests show there is no danger of thermal explosion or detonation under these conditions. 
Finally, as is well known, DMSO can carry dissolved chemicals across the skin membrane into the body. The effect of HMX and other components when administered in this manner is not known. Responsible handling of these chemicals is required at all times. Decomposition products from the firing tank are currently being evaluated for mutagenicity. Strong odor of oxides of sulfur and possibly ammonia were observed after each test and full protective gear was used during cleanup operations. With proper attention to detail, it should be possible to handle these materials as non-explosives.

\section{ACKNOWLEDGMENTS}

The authors gratefully acknowledge both financial and engineering support from DTED especially P. D. Wapman and M. S. Nakano. None of the tests would have been possible without the assistance of $\mathrm{L}$. Crouch and the crew of the $1 \mathrm{Kg}$ tank. Finally, $\mathrm{R}$. Swansiger prepared the DMSO/explosive solutions and R. Garza assisted in the test setup.

\section{REFERENCES}

1. J.M. Pakulak, Jr., and R. Hunt-Kramer, NWC TP 6660, "Simple Techniques for Predicting Sympathetic Detonation And Fast and Slow Cookoff Reactions of Munitions. Naval Weapons Center, China Lake, CA (June 1988)

2. J.M. Pakulak, Jr. and R. Hunt-Kramer, NWC TP 6743, "Thermal Analysis and Cookoff Studies of the Cast Explosive PBXN-103" Naval Weapons Center, China Lake, CA (May 1987)

3. J.M. Pakulak, Jr., "USA Small-scale Cookoff Bomb Test" Minutes of 21 st Explosive Safety Seminar, 1, 539, (Aug. 1984).

4. Transport of Dangerous Goods - NATO Test Manual, ST/SG/AG.10/11, United Nations (1990).

5. US Army Technical Bulletin TB-700-2, "Department of Defense Explosives Hazard Classification Procedures" (December 1.989).

6. DOE Explosives Safety Manual, US Department of Energy, Asst. Sec. for Environment, Safety and Health, Office of Quality Programs, Rev. 6 (Oct. 1991).

7. F. Helm and D. M. Hoffman, "Detonability of DMSO/LX-10-1 and DMSO /PBX 9404 Solutions", Lawrence Livermore National Laboratory, Livermore, CA UCRL-ID117583, (July 1994).

8. NAVORD OD 44811, "Safety and Performance Tests for Qualification of Explosives", Naval Weapons Center, China Lake, CA (1972). 
9. MIL-STD 2105, "Hazard Assessment Tests for Navy Non-Nuclear Ordnance (Sept. 1982)

10. Defense Systems/Nuclear Design Directorate, Facility Safety Procedure, High Explosives Application Facility, Building 191 (June 1993) Lawrence Livermore National Laboratory, Livermore, CA.

11. B.M. Dobratz, LLNL Explosives Handbook, (March 16, 1981) UCRL-52997 (March 1981) Lawrence Livermore National Laboratory, Livermore, CA..

12. A.M. Mellor, T.L. Boggs, J. Covino, C.W. Dickenson, D. Dreitzler, L.B. Thorn, R.B. Frey, P.W. Gibson, W.E. Roe, M. Kirshenbaum and D.M. Mann, Prog. Energy Combust. Sci., 14, 213, (1988).

13. J.W. Frazer and K. Ernst, Exploive Stoffe 12A, (1964)

14. R.N. Rogers, Thermochim. Acta, 11, 131 (1975)

15. J. Zinn and R.N. Rogers, J. Phys. Chem., 66, 2645 (1962).

16. M. Kirshenbaum, US Army Tech Report 4955, Picatinny Arsenal, Dover, NJ. (1976) 


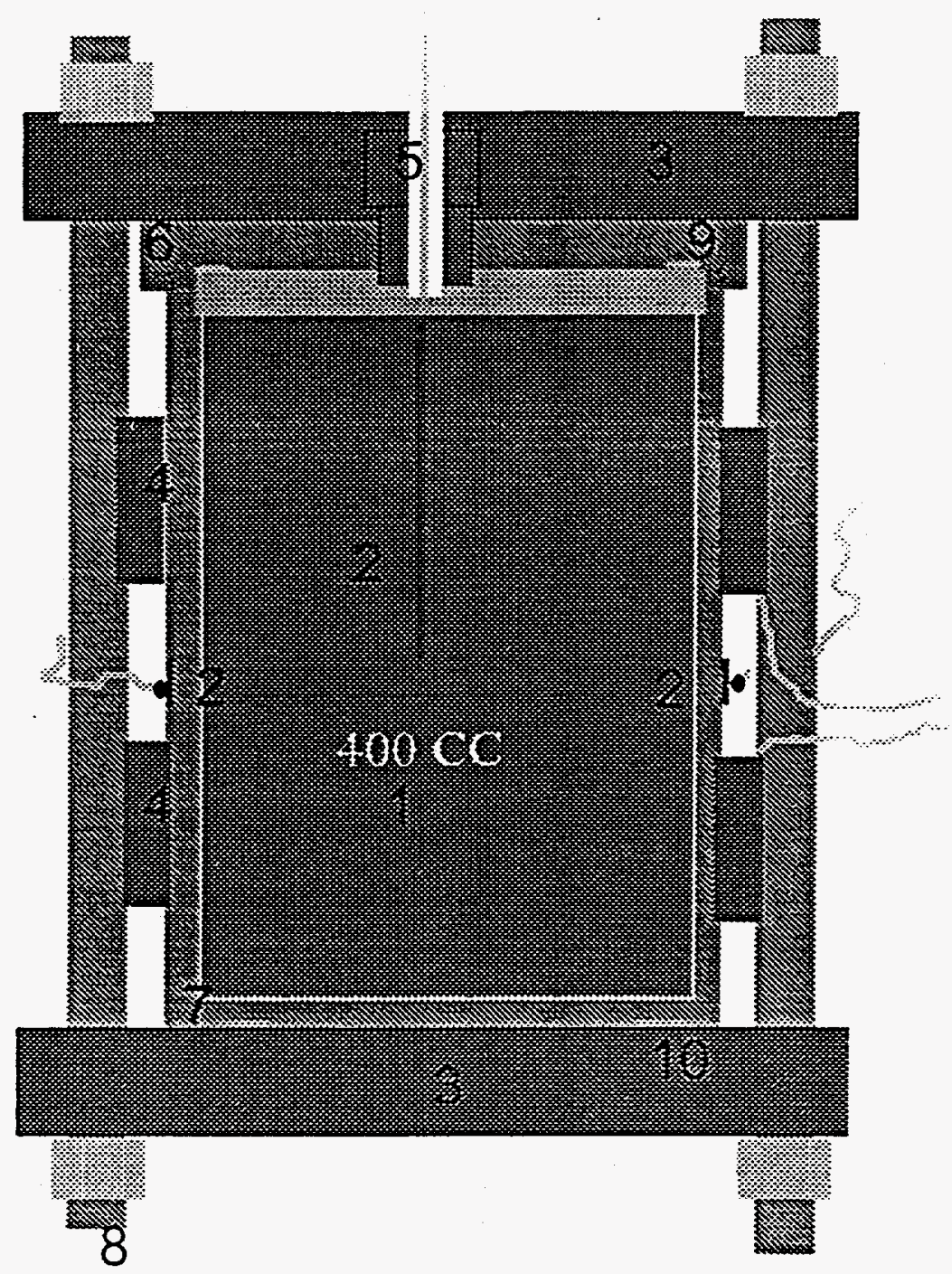

Figure 1. Schematic of Small-Scale Cookoff Bomb shows (1) Test solution of DMSO/PBX with ullage space above, (2) Control, wall and internal thermocouples and electrical wiring, (3) Witness plate, (4) 2400 watt band heaters and electrical wiring, (5) Thermocouple feed through, (6) Cap, (7) Vessel, (8) four Bolts (9) PTFE gasket, (10) Standoff washer. 


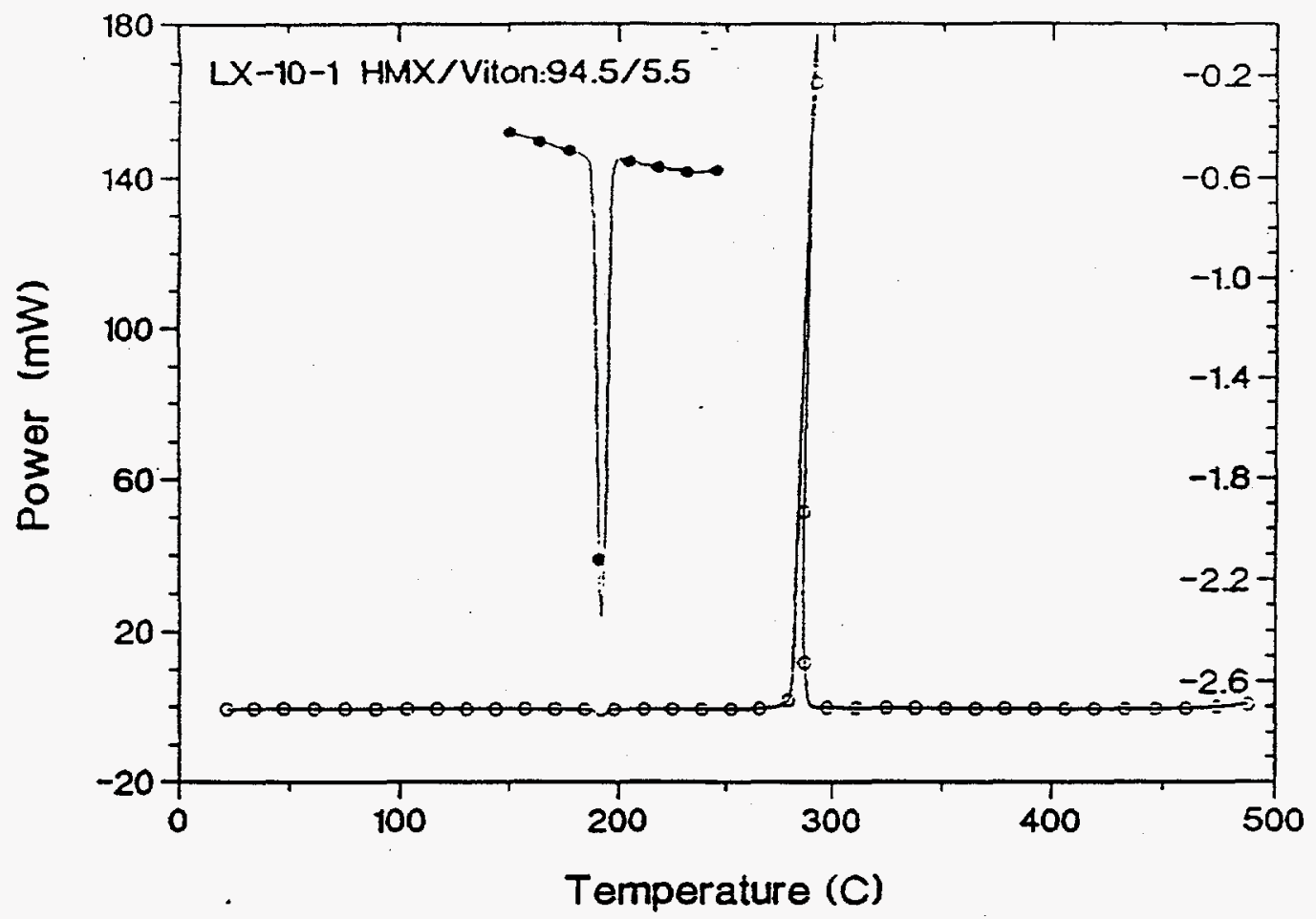

Figure 2. DSC trace of LX-10-1 (insert shows expanded view of HMX phase change).

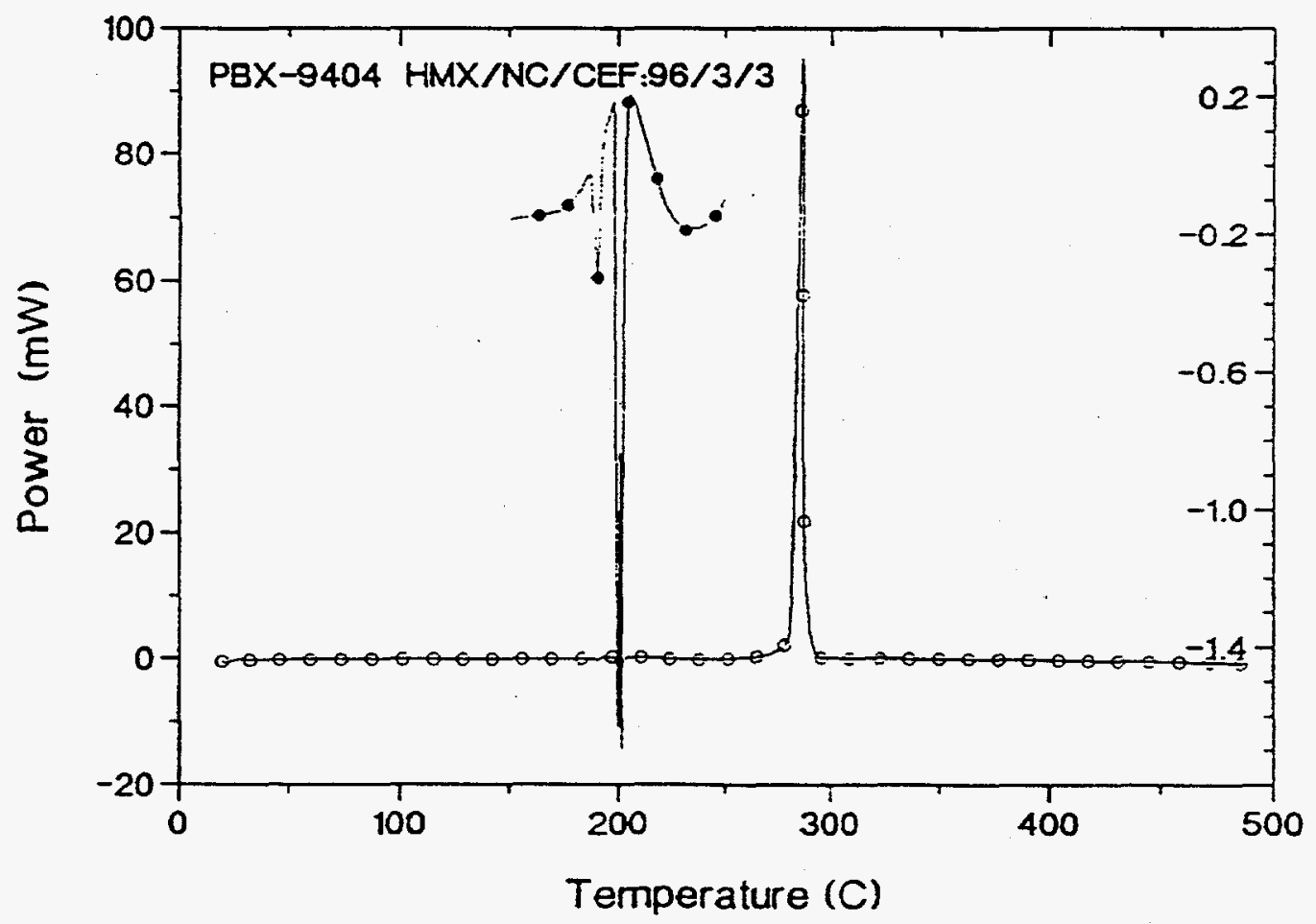

Figure 3. DSC trace of PBX-9404 (insert shows NC decomposition and phase change). 


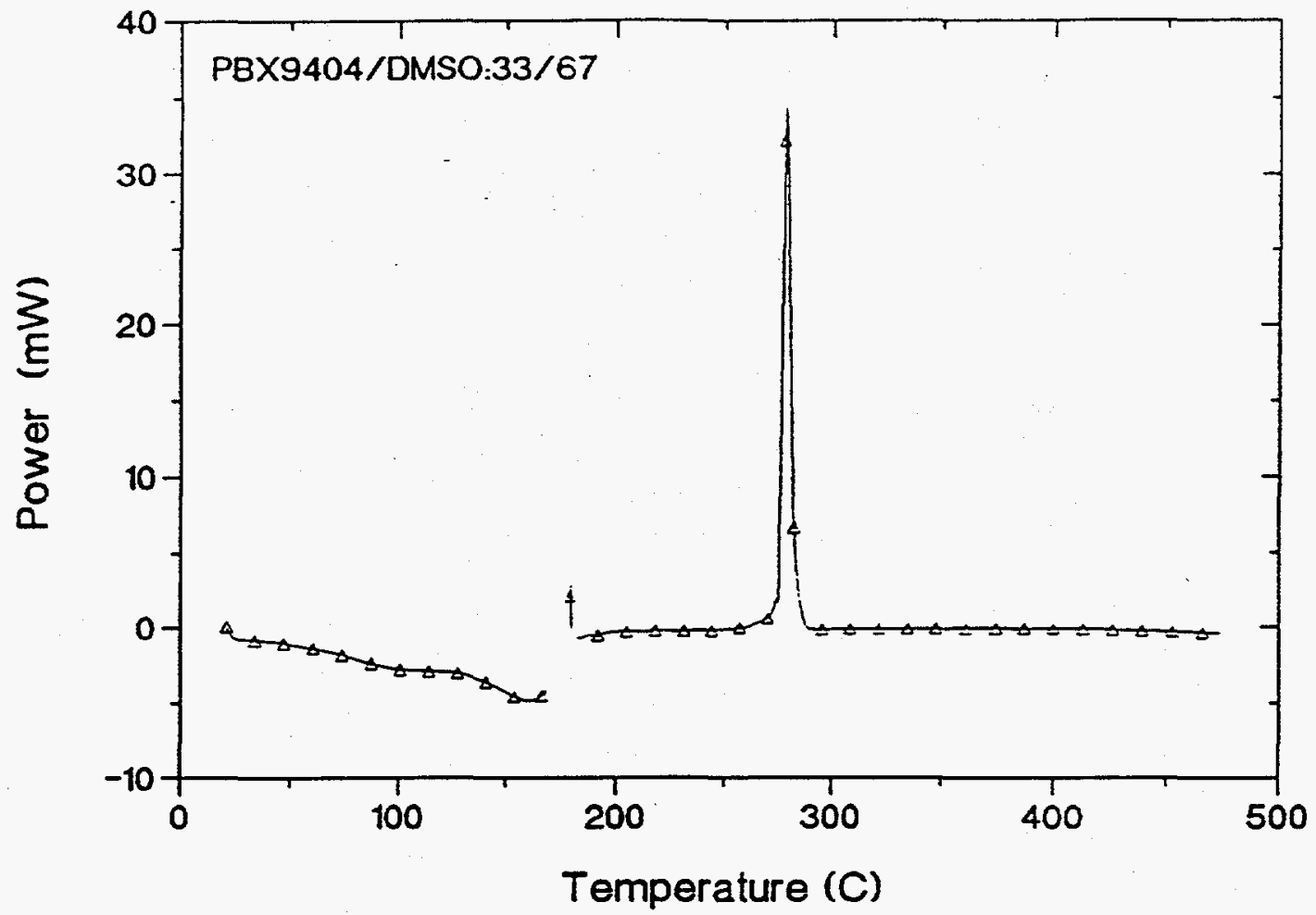

Figure 4. DSC trace of solutions of 33/67:PBX-9404/DMSO shows vaproization of DMSO and exothermic decompoisition of HMX.

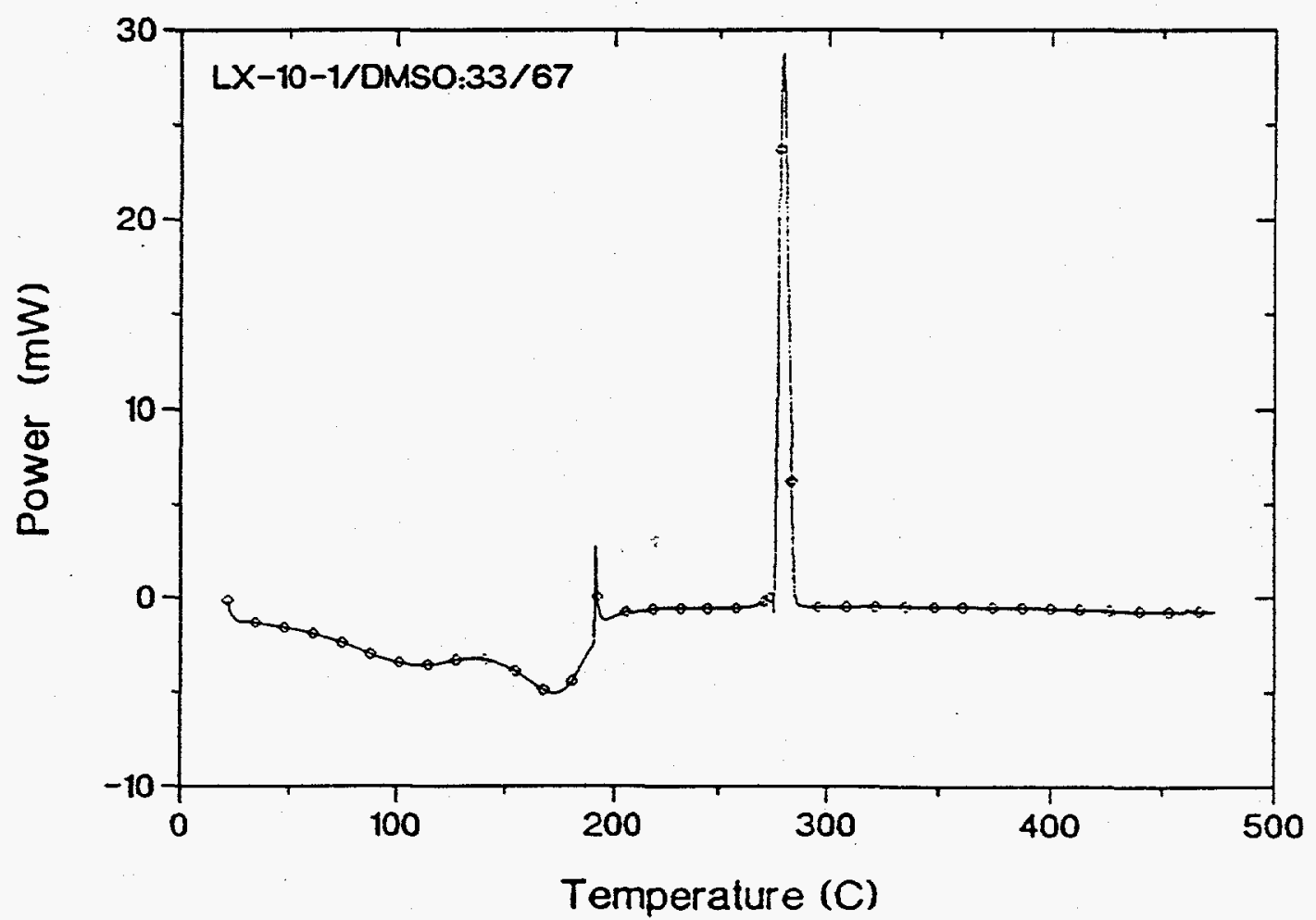

Figure 5. DSC trace of solution of 33/67:LX-10-1/DMSO is similar to Figure 3. 



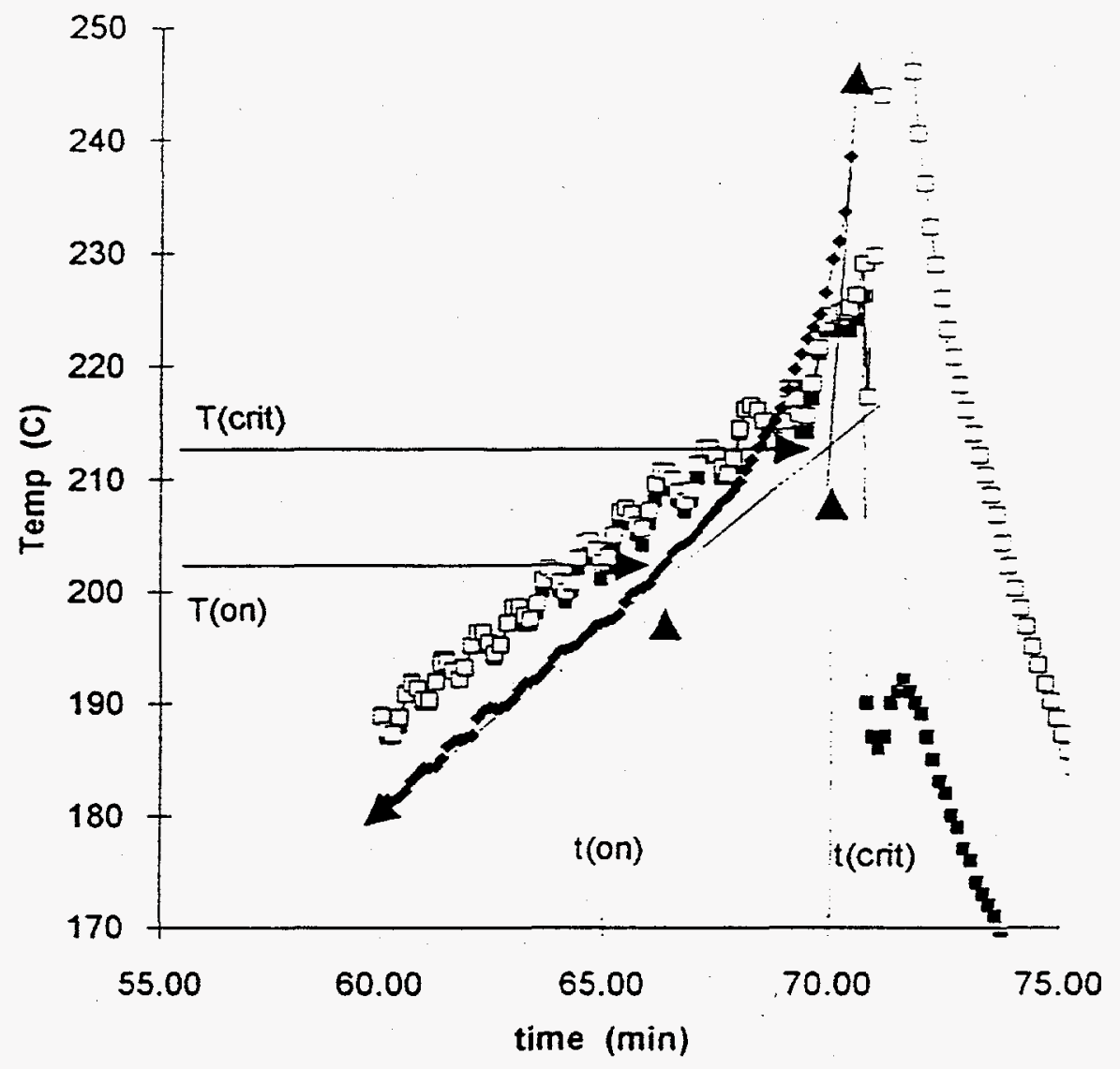

Figure 7. Enlarged plot of thermocouple readouts from DMSO/PBX9404:75/25 UN cook off test shows method used to identify onset and critical times and temperatures from each test. 


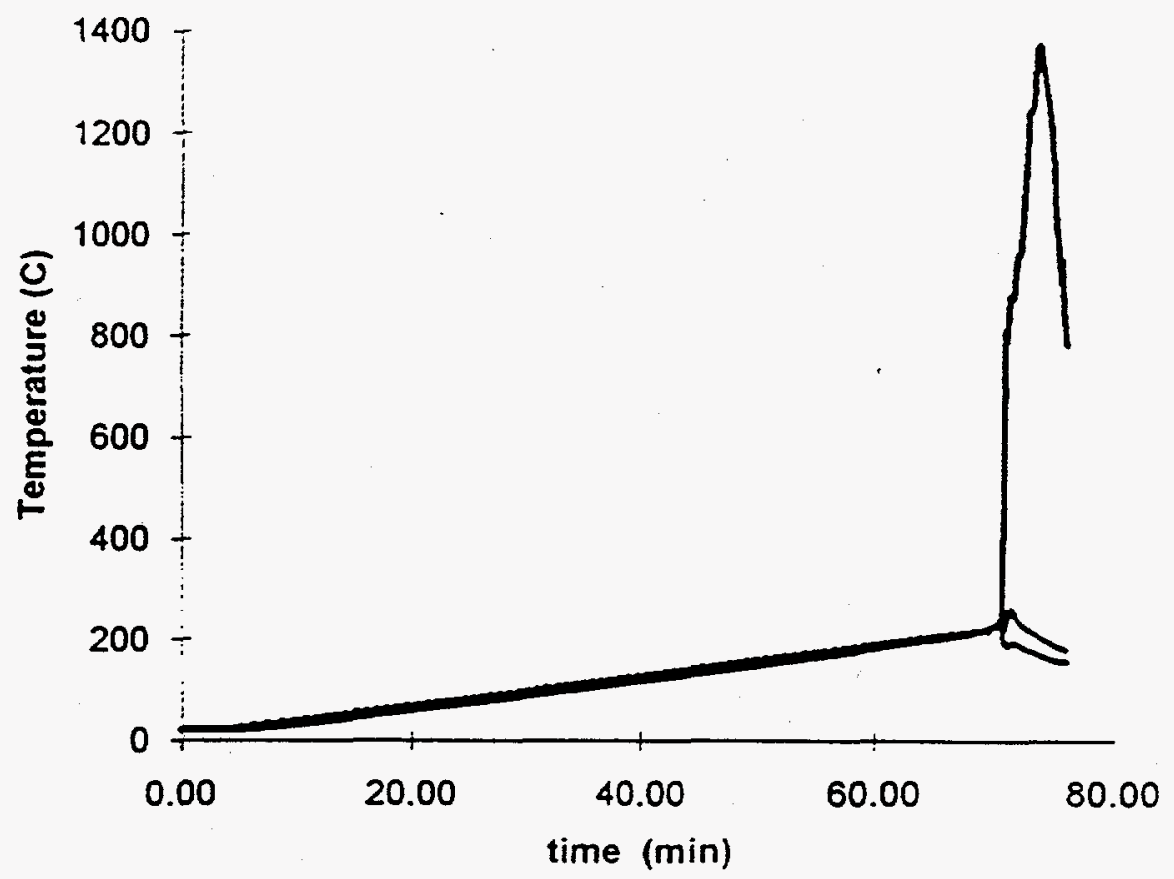

Figure 8. Plot of thermocouple readouts from DMSO PBX9404:75/25 UN cook off test $\neq 1$.

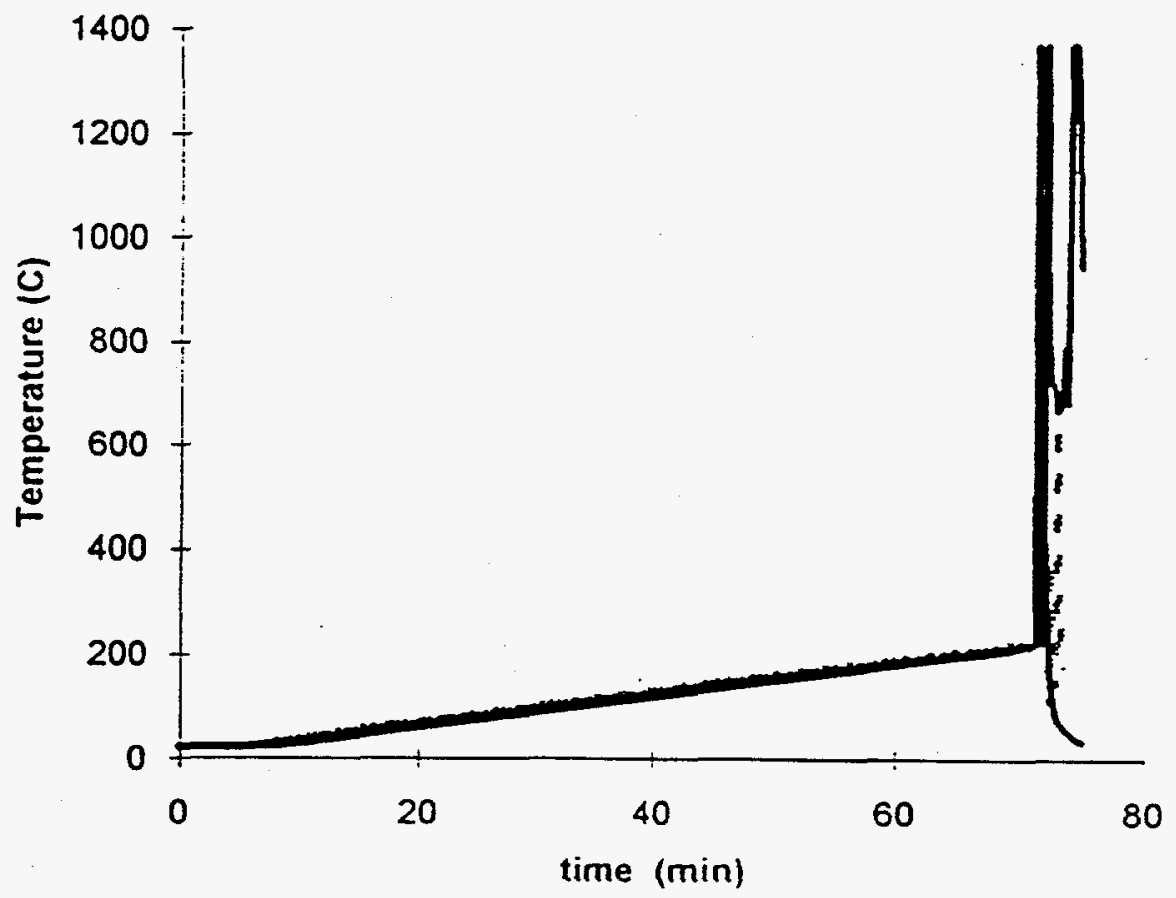

Figure 9. Plot of thermocouple readouts from DMSO PBX9404:75/25 UN cook off test $\# 2$. 


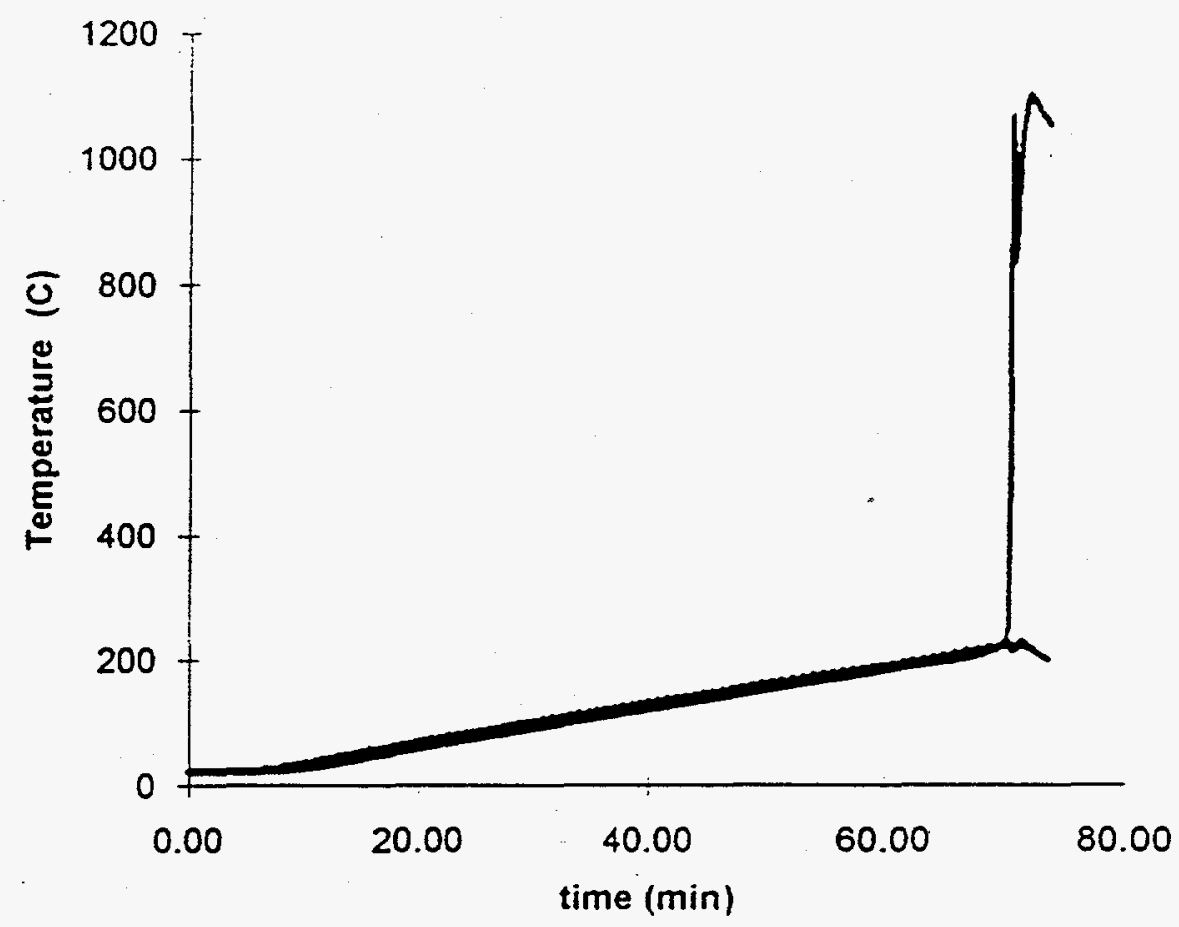

Figure 10. Plot of thermocouple readouts from UN cook off test $\bar{\mp}$ (DMSO/PBX9404:75/25).

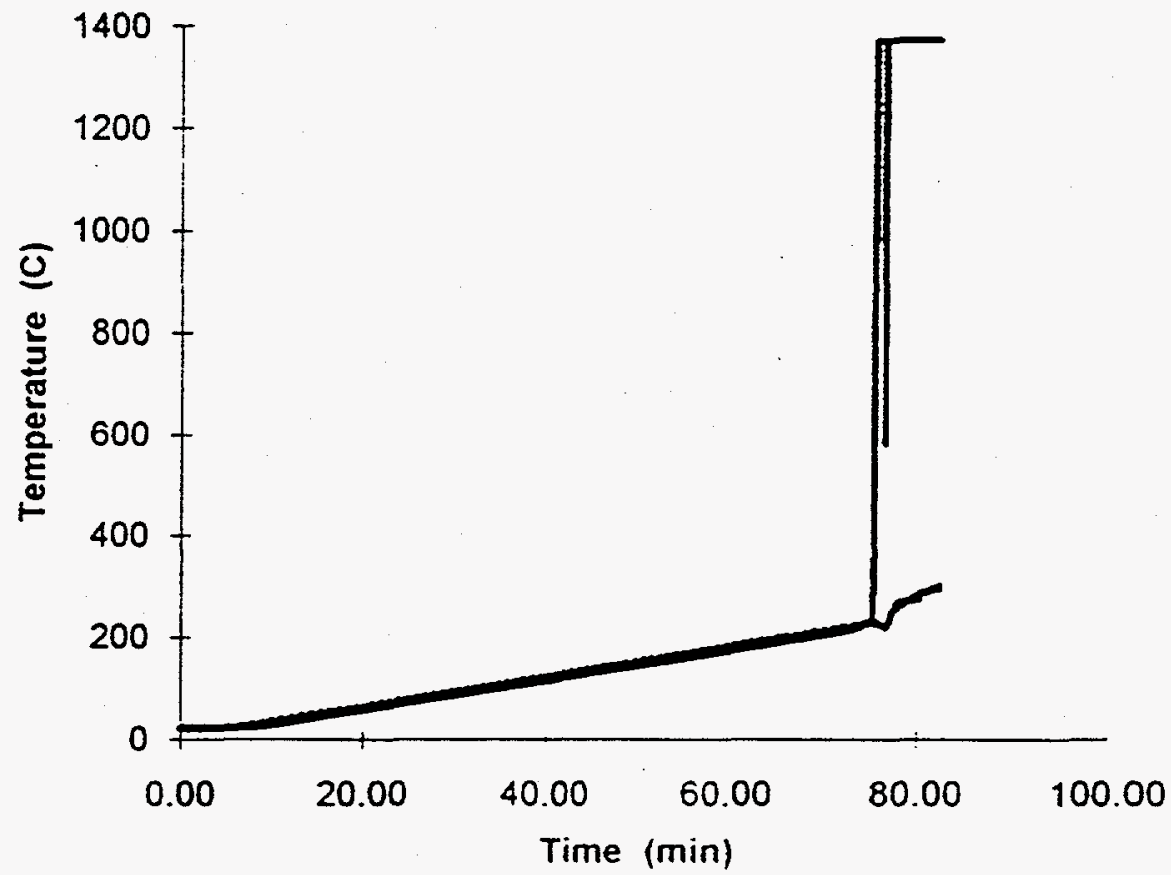

Figure 11. Plot of thermocouple readouts from UN cook off test $\# 4$ (DMSO/LX-10-1:75/25). 


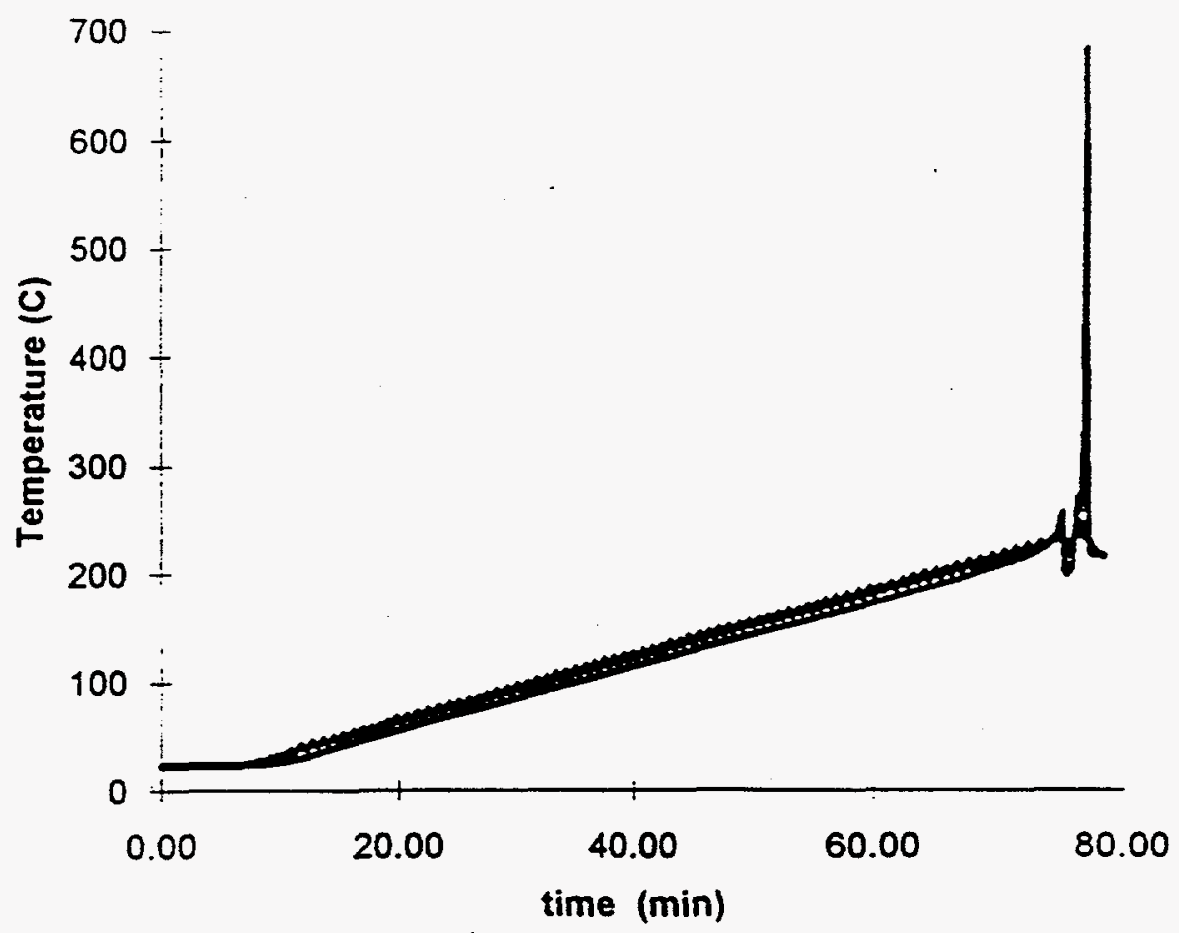

Figure 12. Plot of thermocouple readouts from UN cook off test \#5 (DMSO/LX-10-1:75/25).

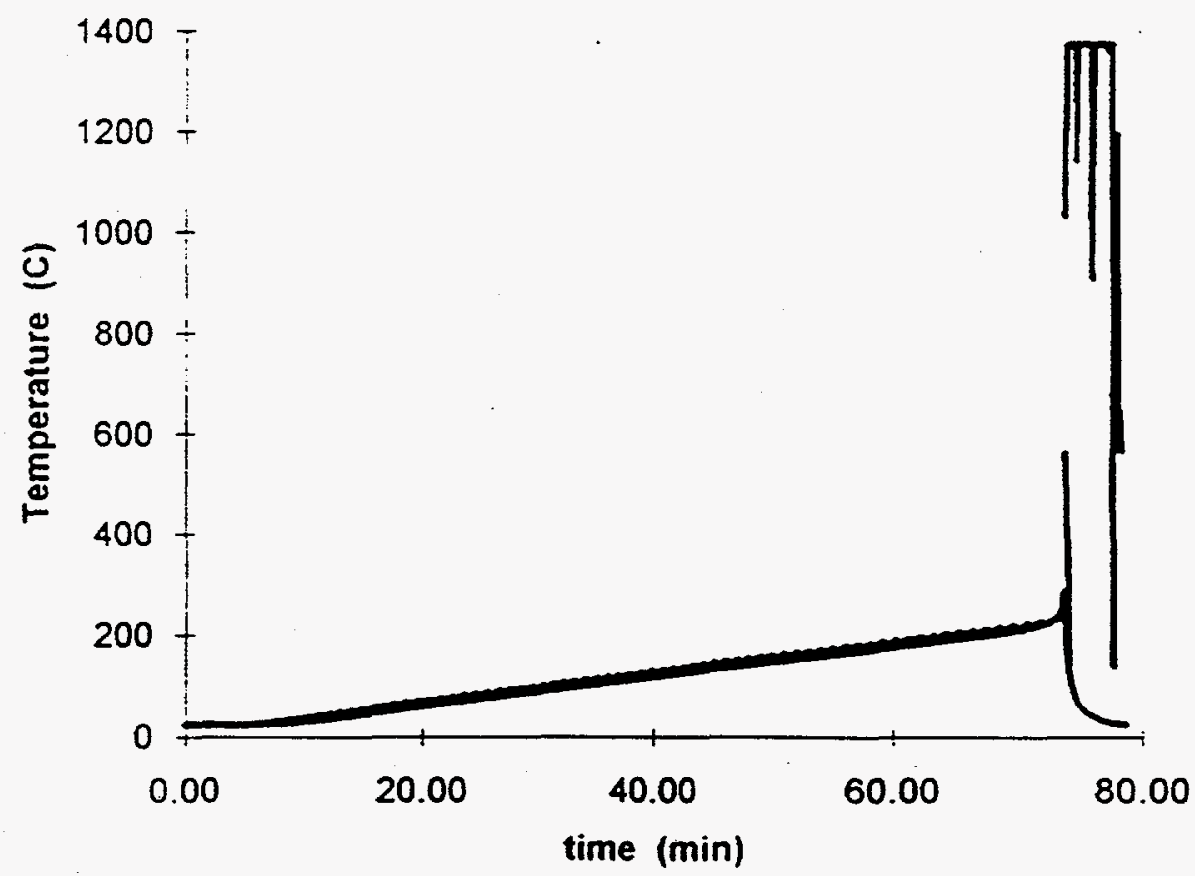

Figure 13. Plot of thermocouple readouts from UN cook off test \#6 (DMSO/LX-10-1:75/25). 

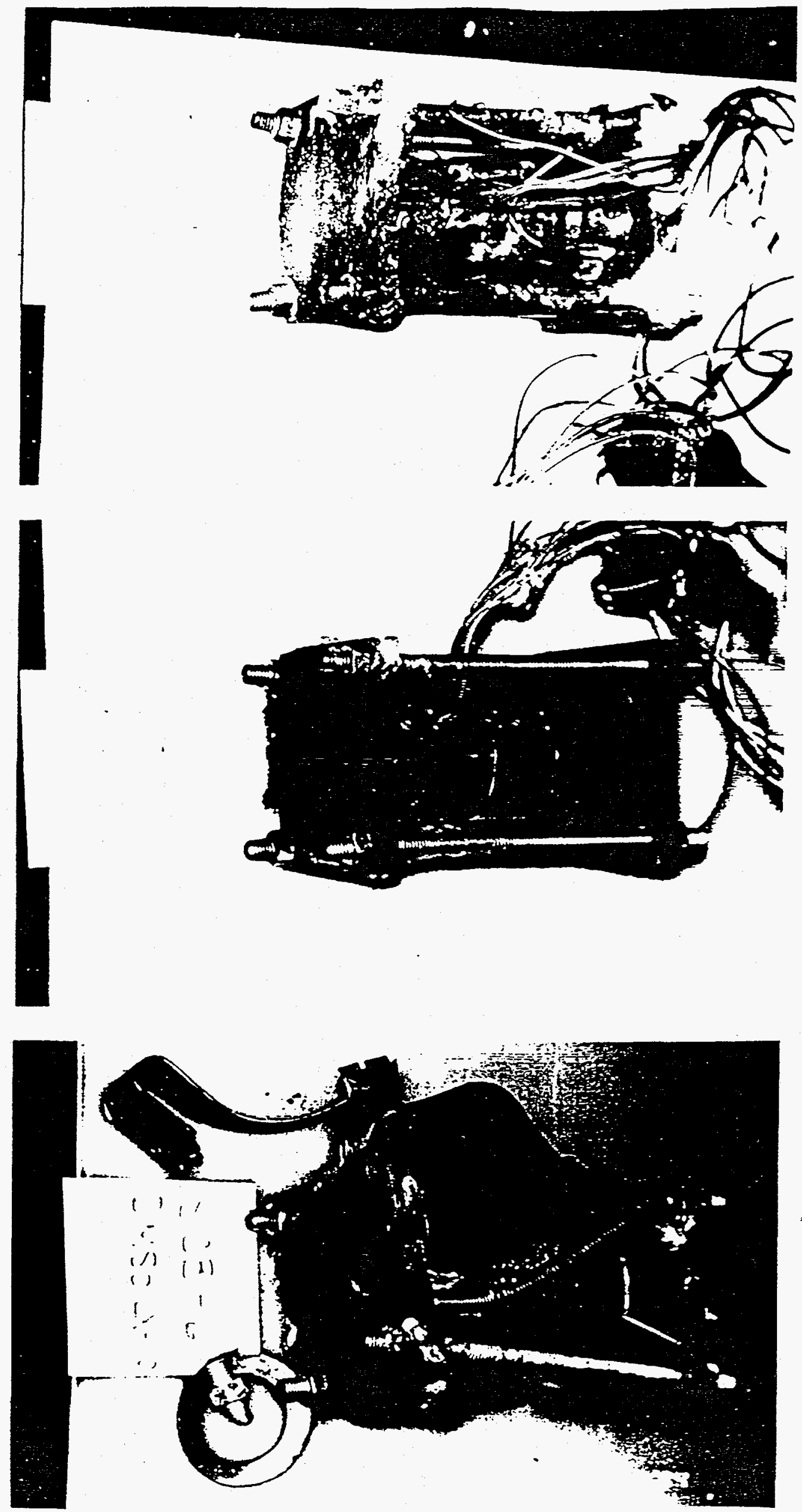

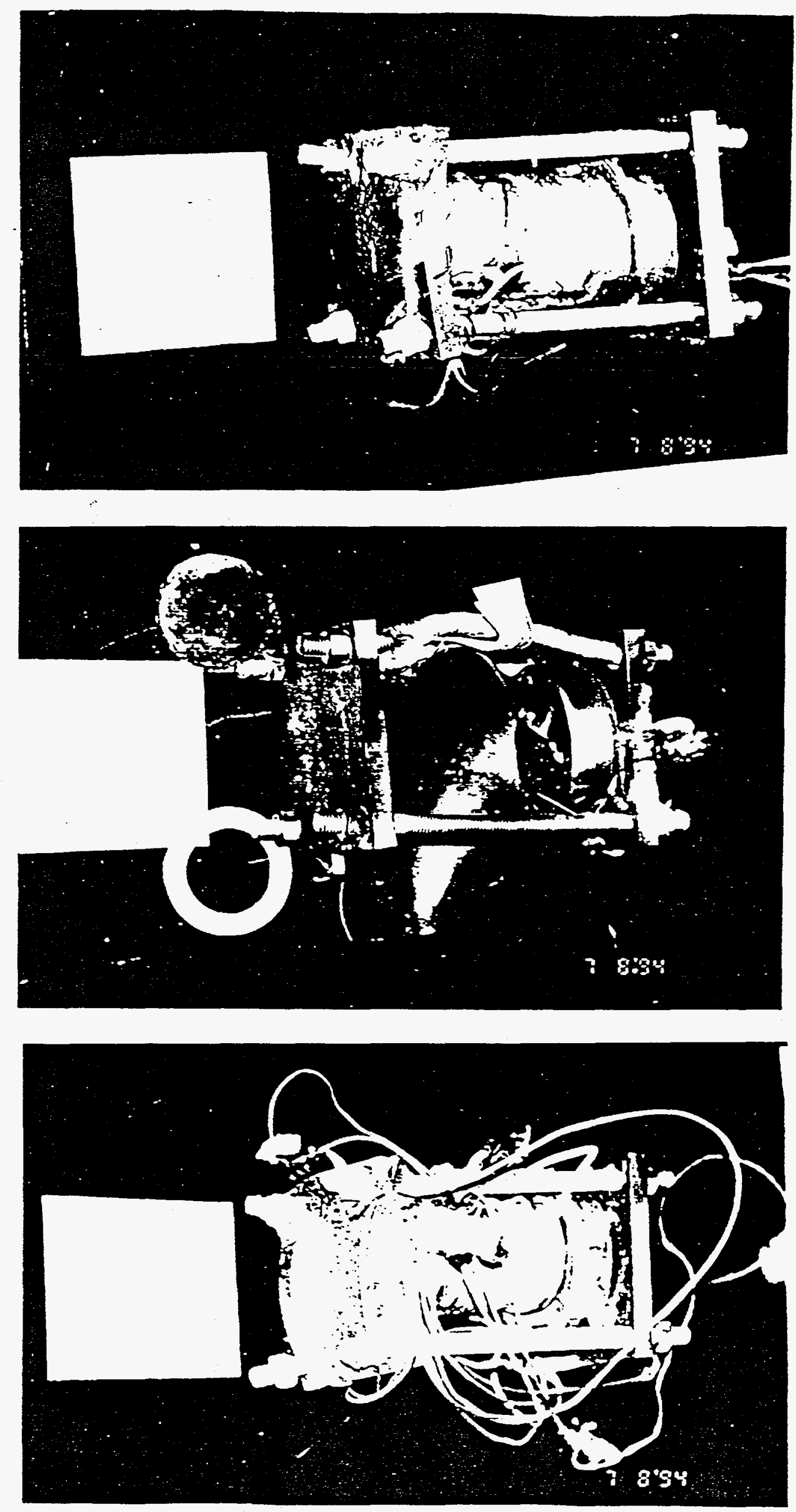


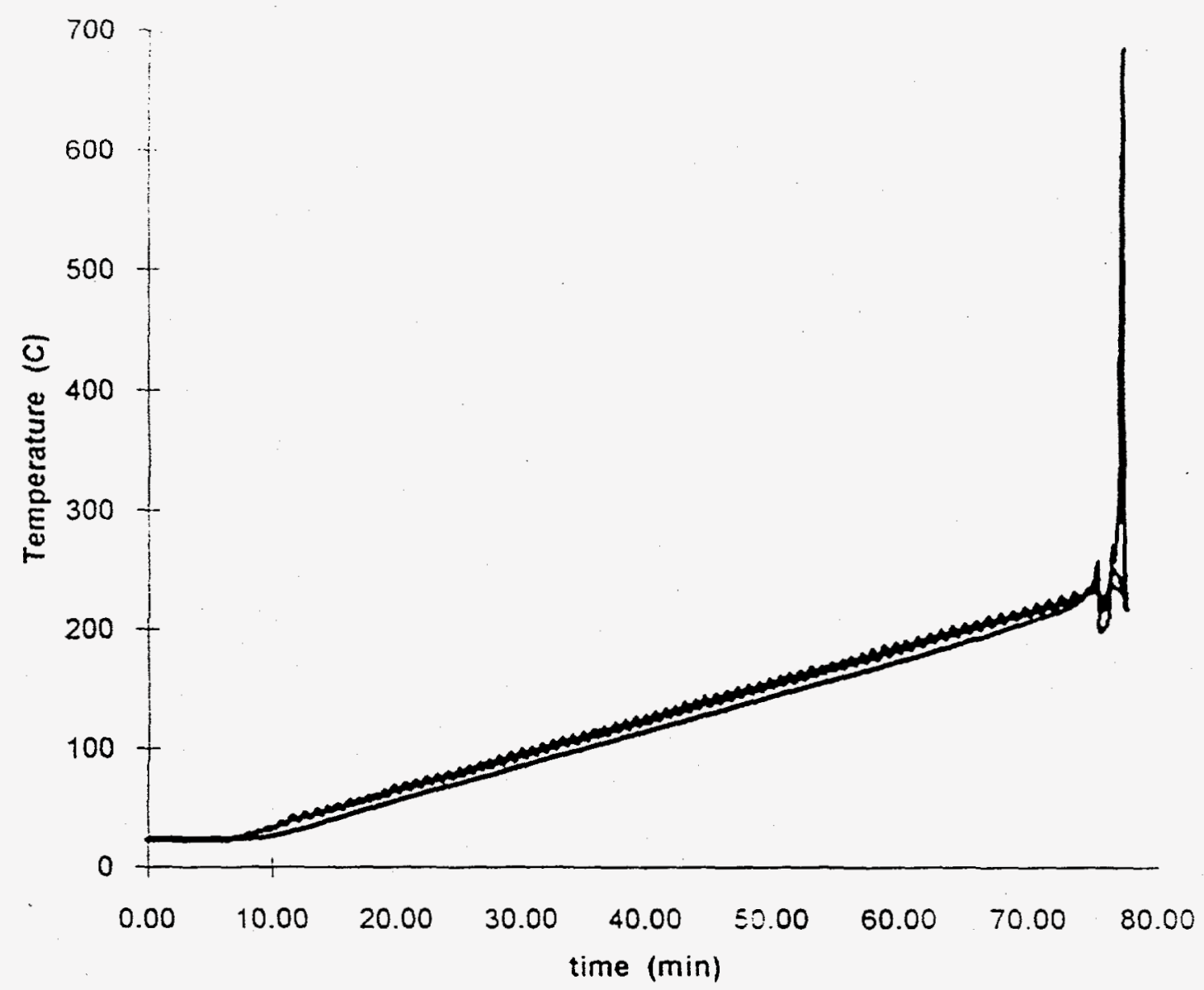

Figure 17. Plot of thermocouple readouts from $\mathrm{CX}^{2}$ : $20 \mathrm{k}$ orf test $=^{-}$(DMSO only). 


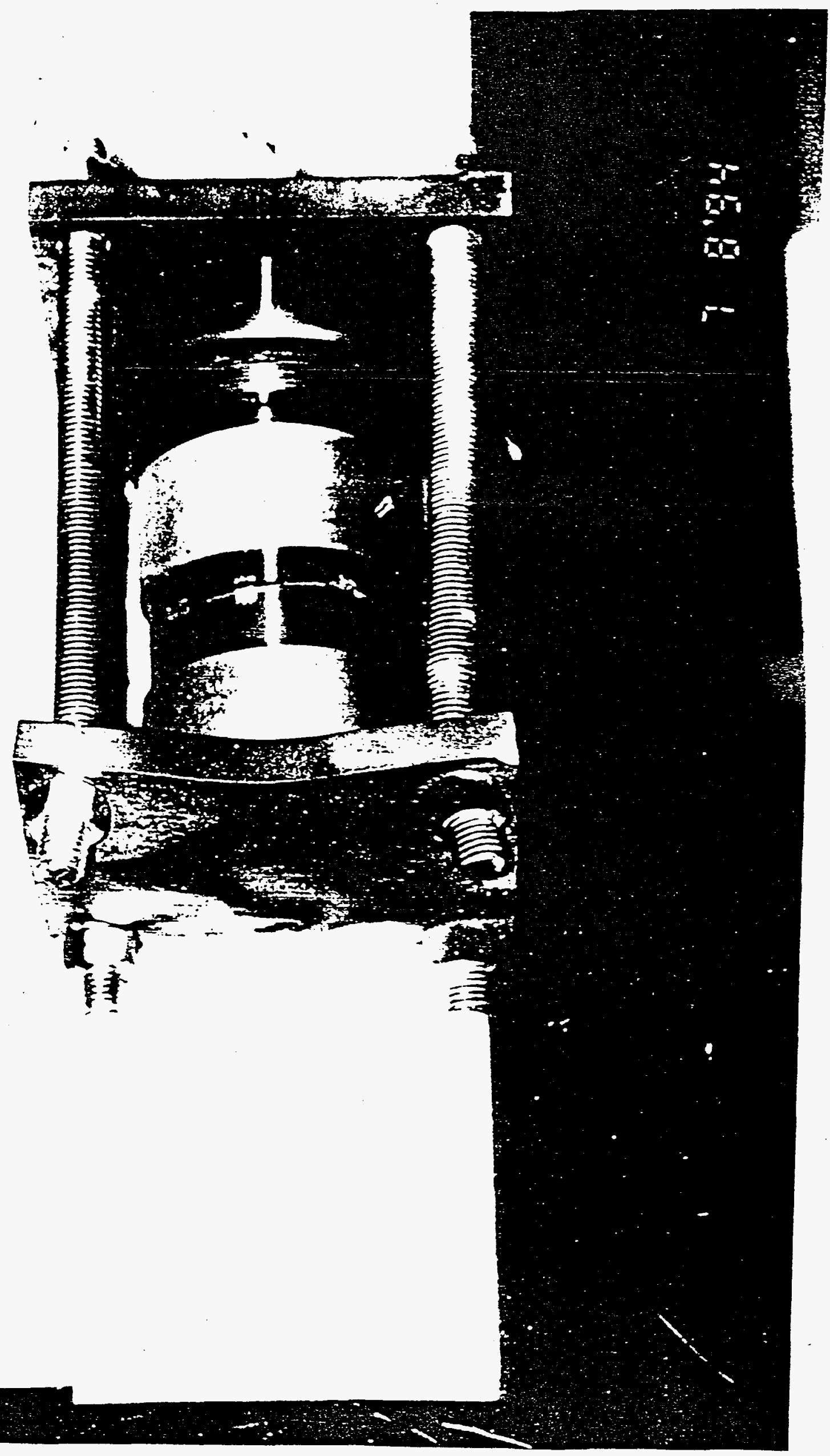

